\title{
SEVERE HYPOGLYCAEMIA IN A WOMAN WITH SECONDARY HYPOADRENALISM AND AN ABNORMAL PITUITARY STALK, COMPLICATING METASTATIC BREAST CANCER
}

\author{
KAMATH C, PREMAWARDHANA LD, ADLAN MA
}

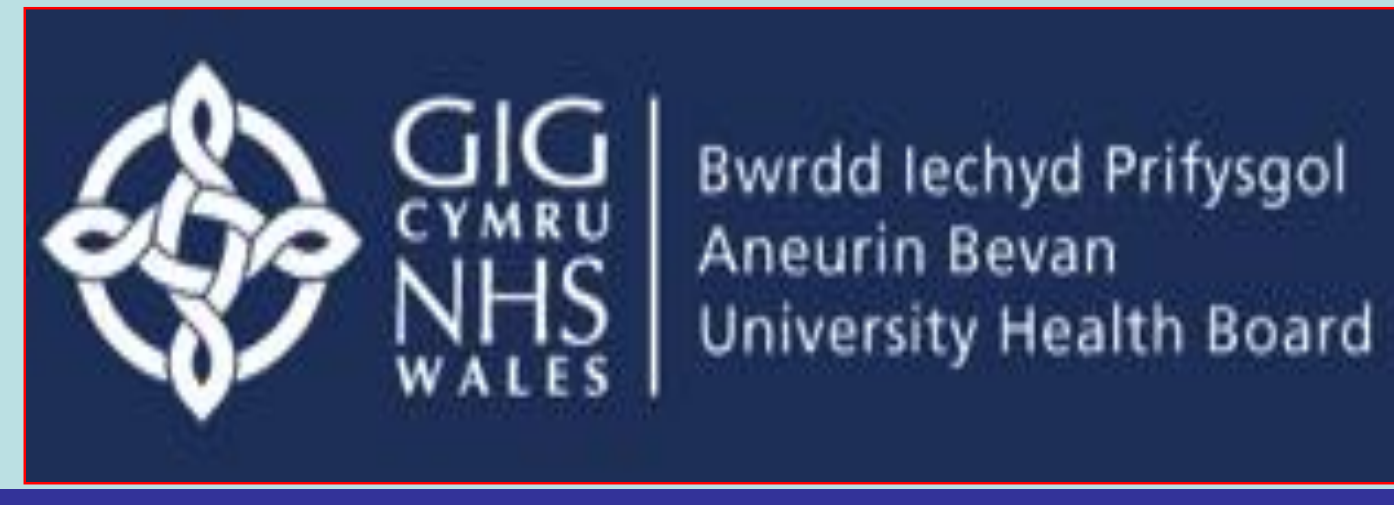

\section{Section of Endocrinology, Aneurin Bevan University Health Board, Ysbyty Ystrad Fawr, Caerphilly CF82 7EP, UK}

\section{BACKGROUND}

Significant hypoglycaemia is a rare but well recognised presenting feature of secondary adrenal insufficiency. Such hypoadrenalism may be caused by intrinsic hypothalamo-pituitary disease (e.g. pituitary adenoma), exogenous steroid therapy, and rarely by hypophysitis and pituitary secondaries from malignant disease.

\section{CASE PRESENTATION}

A 73-year-old woman with a previous diagnosis of ulcerative colitis, presented acutely with confusion, agitation, and aggressive behaviour. She had been unwell for many months and had lost $3 \mathrm{~kg}$ in weight unintentionally. She was on mesalazine and took no other medication. She did not smoke and drank alcohol rarely.

On examination she was thin and pale, had a pulse of 70/minute, blood pressure was $137 / 78$ with no postural drop, and her temperature was $33.3 \mathrm{C}$. Systems examination was entirely normal. Paired capillary and venous plasma glucose levels ( 0.3 and $2.2 \mathrm{mmol} / \mathrm{l}$ respectively) were low. She was given intravenous dextrose immediately.

\section{RESULTS OF INVESTIGATIONS}

\begin{tabular}{ll}
\hline INVESTIGATION & RESULTS \\
Short Synacthen test & $\begin{array}{l}\text { Cortisol }-0 \text { min 56; } 30 \text { min } 297 \\
n m o l / /{ }^{* *}\end{array}$ \\
Adrenal antibodies & Negative
\end{tabular}

Adrenal antibodies Negative

Gonadotrophins and LH - 0.1; FSH $2.4 \mathrm{mmol} / \mathrm{l}$;

Oestradiol

Prolactin

Thyroid function

IGF1/IGF2 ratio,

Gut hormone profile,

Insulin antibodies

CA 15-3

\section{Oestradiol $37^{* *}$}

734 **

TSH $0.81 \mathrm{mU} / \mathrm{l}$; free T4 - $9.1 \mathrm{pmol} / \mathrm{l}$ Normal

\section{Table 1}

Results show hypoadrenalism,

hypogonadotrophic

hypogonadism and mild

hyperprolactinaemia; marker for

breast cancer $+v e$

Figures 1 and 2

Coronal and sagittal sections of contrast enhanced MRI scans

of the pituitary showing a

macroadenoma and a

thickened pituitary stalk (red

arrows)

\section{Figure 3}

Nuclear magnetic bone scan showing multiple secondaries in the spine, skull and pelvis

A bone biopsy of the pelvis

(red arrow), showed

histological features

consistent with secondaries

from an adenocarcinoma of

the breast (despite normal

CT and mammography) **

1 Site of biopsy

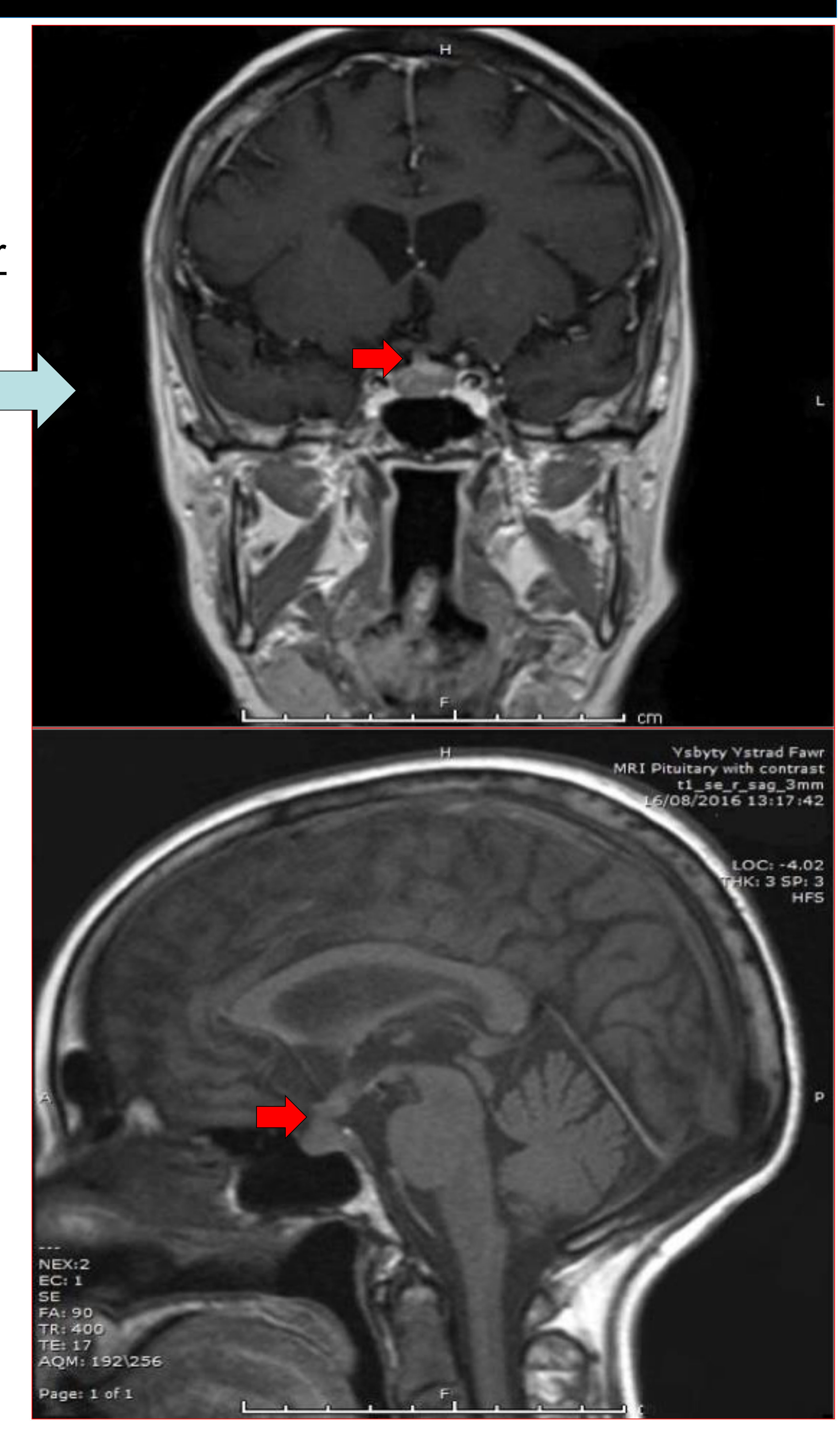

\section{CONCLUSIONS}

(1) Severe hypoglycaemia is an uncommon presenting feature of secondary hypoadrenalism

(2) Secondary hypoadrenalism needs to be considered as a cause in the differential diagnosis of hypoglycaemia

(3) Our patient had partial anterior hypopituitarism likely due to pituitary metastases from a hitherto undiagnosed breast carcinoma.

(4) Although hypophysitis and a pituitary adenoma causing secondary hypoadrenalism are also possible, the findings of multiple bony secondaries and pituitary imaging features make pituitary secondaries likely

(5) The primary in this patient was an undiagnosed breast adenocarcinoma as proved by bone biopsy 